\title{
Ion pairing and dielectric decrement in glycosaminoglycan brushes
}

\author{
James D. Sterling ${ }^{\dagger}$ Wenjuan Jiang $₫$, Wesley M. Botello-Smith ${ }^{\ddagger}$, Yun L. Luo \\ ${ }^{\dagger}$ Henry E. Riggs School of Applied Life Sciences, Keck Graduate Institute, \\ 535 Watson Dr., Claremont, California, 91711, United States \\ $\$$ College of Pharmacy, Western University of Health Sciences, 309 E. Second St., Pomona, \\ California, 91766, United States
}

Correspondence: jim sterling@kgi.edu or luoy@westernu.edu

\begin{abstract}
Molecular dynamics simulations of hyaluronic acid and heparin brushes are presented that show important effects of ion-pairing, water dielectric decrease, and co-ion exclusion. As in prior studies of macromolecular crowding under physiologically-relevant salt concentrations, our results show equilibria with electroneutrality attained through screening and pairing of brush anionic charges by cations. Most surprising is the reversal of the Donnan potential that would be expected based on electrostatic Boltzmann partitioning alone. Water dielectric decrement within the brush domain is also associated with Born hydration-driven cation exclusion from the brush. We observe that the primary partition energy attracting cations to attain brush electroneutrality is the ion-pairing or salt-bridge energy associated with cation-sulfate and cation-carboxylate solvent-separated and contact ion pairs. Potassium and sodium pairing to glycosaminoglycan carboxylates and sulfates consistently show similar abundance of contact-pairing and solvent-separated pairing. In these crowded macromolecular brushes, ion-pairing, Born-hydration, and electrostatic potential energies all contribute to attain electroneutrality and should therefore contribute in mean-field models to accurately represent brush electrostatics.
\end{abstract}




\section{INTRODUCTION}

Glycosaminoglycans (GAGs) are macromolecular polysaccharides whose interactions are governed largely by electrostatic salt-bridges between their anionic charges and cations and/or cationic residues of proteins ${ }^{1-3}$. As cell-surface and extracellular macromolecules, GAGs play important roles in angiogenesis, inflammation, immunity, and cell penetration processes. ${ }^{4-8}$ The binding of heparan sulfate proteoglycans (HSPGs) to their protein interactome of at least 300 growth factors, chemokines and cytokines depends on ion pairing between the heparan sulfates (HS) and the basic domain sequences of the proteins; interactions which can be considered targets for therapeutic intervention. ${ }^{9-11}$ Based on these electrostatic interactions, heparin has a long history of application in affinity chromatography. ${ }^{12,13}$ Recently, HSPG-binding has been shown to mediate cell uptake of tau protein, $\alpha$-synuclein, and $\beta$-amyloid aggregates elucidating a role of GAGs in neurodegenerative disease as well as in viral infectious disease including the SARS-CoV-2 virus. ${ }^{14-17}$ As intrinsically-disordered macromolecules, GAGs can also partition ions and cationic macromolecules to form liquid-liquid phase separations and coacervates. ${ }^{18}$

In these biological roles, proteoglycans and mucins are typically 100s of kilodaltons to over 10 megadalton macromolecules that form a glycan-rich region called the glycocalyx. The glycocalyx at mucosal surfaces, endothelial surfaces, tissue interfaces, as well as tumor cell surfaces act as a set of tethered macromolecular polyelectrolytes, forming microscale anionic domains that partition ions to attain electroneutrality. Several studies have shown that the net/integral anionic charge density often plays a more important role in binding activity than specific sulfation patterns. ${ }^{1,2,15,19}$ A number of important biophysical effects have been studied in efforts to elucidate quasiequilibrium geometry, composition and electrostatic state of the glycocalyx. Biophysical models of the glycocalyx as polysaccharide hydrogels, soft diffuse interfaces, or polyelectrolyte brushes have been developed and several research groups have recently applied electrokinetic methods to measure ionic conductivity within the polymer region ${ }^{19-24}$. These measurements often utilize fitting with mathematical mean-field models to determine polymer density, electrostatic/Donnan potential and, if charge densities are not dilute, ion-pair binding constants to match measured surface conductivity ${ }^{25-27}$.

Atomistic simulations can be used to investigate brush properties and link the molecular dynamics (MD) derived properties to a mean-field theory. Here, we use all-atom MD simulations at the nanoscale to identify emergent properties that can be used in mean-field microscale models to improve our understanding of a model glycocalyx brush. We start by describing the computational methods and setup for the simulation of hyaluronic acid and heparin brushes bounded by $\mathrm{NaCl}$ or $\mathrm{KCl}$ solutions. The results and discussion section follows with a report on the collapse of the brush from a fully-extended state and the resulting charge densities in the brush and bulk regions. We then evaluate the electrostatic potential in the brush relative to the bulk salt using the Particle Mesh Ewald (PME) method and we compute the dielectric decrement of the water in the two regions and estimate the Born hydration energies for the cations in those regions. The role of ion-pairing 
of the cations to specific oxygen atoms of the anionic carboxylates and sulfates in the GAGs is then presented. We conclude by postulating a cation-centric mean-field model for the GAG brushes that includes electrostatic, Born-hydration, and ion-pairing energies that govern quasistatic electroneutrality.

\section{COMPUTATIONAL METHODS}

Simulated Systems: MD simulations to assess the variability of brush integral charge density were performed by using uniform-disaccharide models of the least-charged (-1e per disaccharide) and most highly-charged (-5e per disaccharide) GAGs; hyaluronic acid and oversulfated heparin as used by Stopschinski et.al. in their study of sulfation associated with Tau internalization. ${ }^{15}$ Under physiological $\mathrm{pH}$, the oversulfated heparin disaccharide, GlcA2S $\alpha 4 \mathrm{GlcNS} 3 \mathrm{~S} 6 \mathrm{~S} \alpha 4$, has five negative charges and the hyaluronan disaccharide, GlcA $\beta 3$ GlcNAc $\beta 4$ has one negatively-charged carboxylate. The brush model we considered was a grid of GAG molecules of 16-disaccharide units tethered by a fixed oxygen atom of the $(1 \rightarrow 4)$ glycosidic bond in the middle of the molecules that are placed in the middle (defined as horizontal axis $\mathrm{z}=0$ ) of the orthorhombic periodic box of $480 \AA$ in length. Figure 1 shows the molecular structure of the oversulfated heparin.
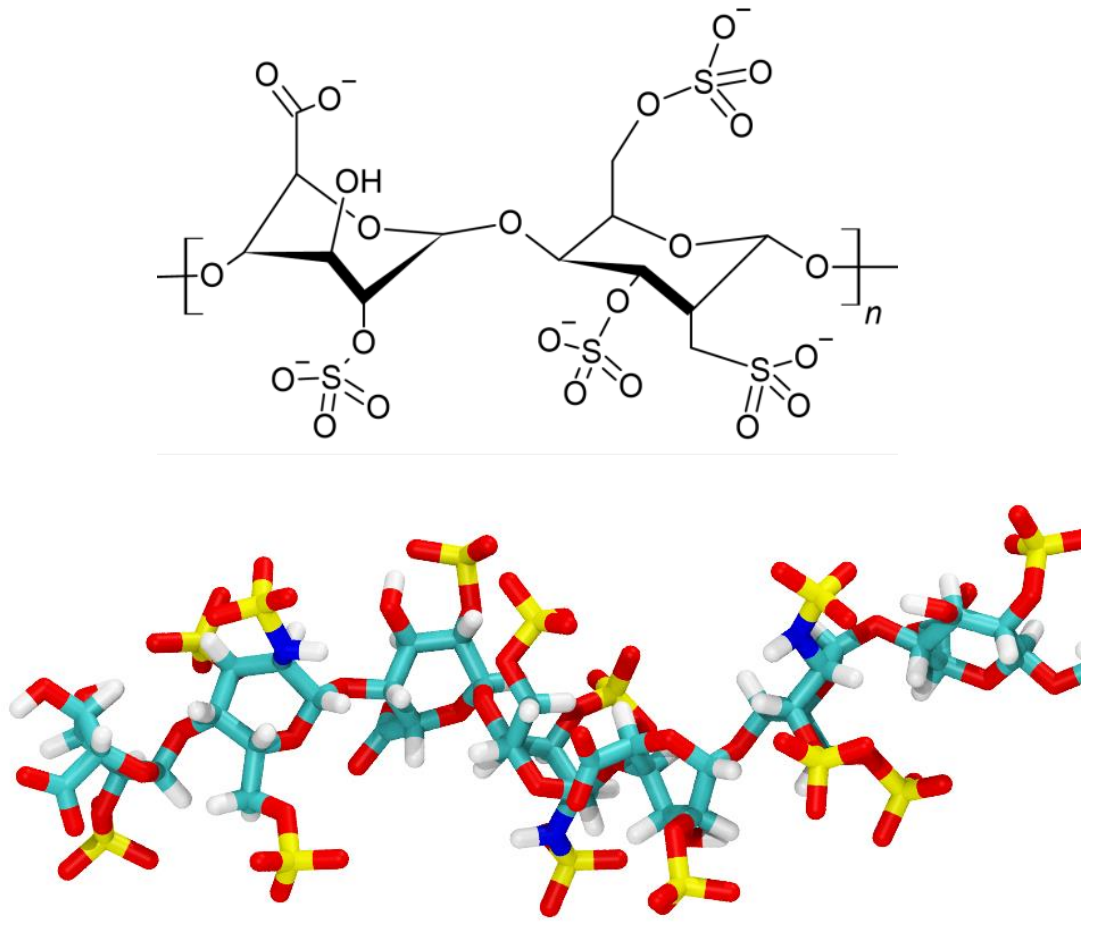

Figure 1: Molecular structure of oversulfated heparin glycosaminoglycan with repeating disaccharide GlcA2S $\alpha 4$ GlcNS3S6S $\alpha 4$. The upper image shows the chemical structure and bottom image shows the chemical geometry in VMD using the color scheme: oxygen in red, nitrogen in blue, sulfur in yellow, carbon in cyan, hydrogen in white. 
We emphasize that there is no solid surface or substrate to which the molecules are tethered. The brush is formed by a $20 \AA$ x $20 \AA$ array of four of these GAG molecules as shown in Figure 2 in the fully-extended initial state ( $\mathrm{t}=0, \sim 160 \AA$ length since each disaccharide is $\sim 10 \AA$ long), and in the collapsed quasi-steady state $(\mathrm{t}=100 \mathrm{~ns})$. The periodic boundary conditions (PBC) are applied which create an infinite lattice of the brush in the $\mathrm{x}-\mathrm{y}$ plane that is surrounded by saline solution of near $250 \mathrm{mM}$ (Debye length near $6 \AA$ ). Ion-specific behavior is assessed by simulating $\mathrm{NaCl}$ and $\mathrm{KCl}$ solutions in both the hyaluronan and heparin GAGs to give four salt-GAG combinations. Our simulations represent tethered strong polyelectrolytes in the extended ionizable osmotic-brush regime. ${ }^{27-29}$ However, we emphasize that sulfate and carboxylate anions are not protonated but that ion pairing with the salt cation is present instead.

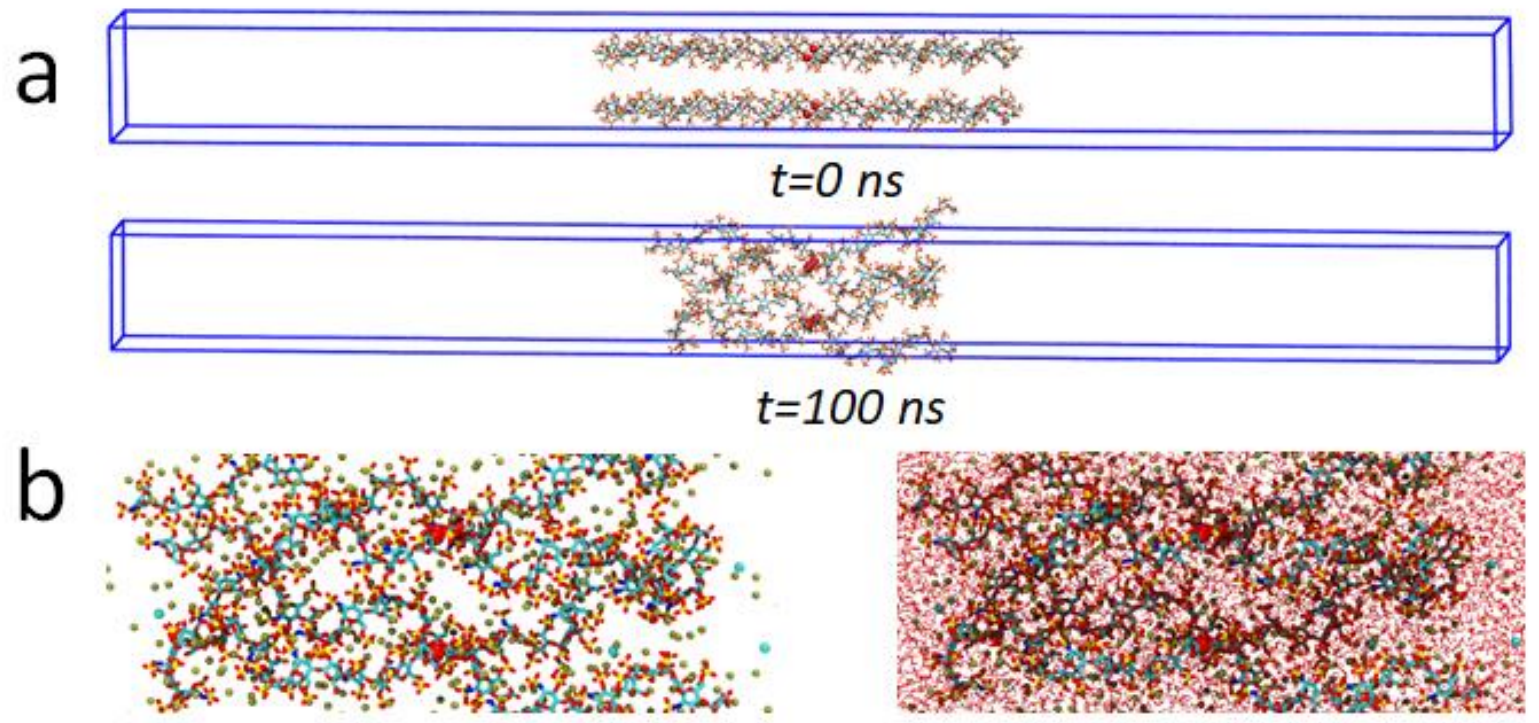

Figure 2. Representative simulation system (a) System with initial fully-extended four 16disaccharide GAG molecules tethered at center $(z=0)$ in unit cell forming a $40 \AA \mathrm{x} 40 \AA \mathrm{x} 480 \AA \mathrm{x}-$ $\mathrm{y}-\mathrm{z}$ (depth-height-width) simulation box. The initial heparin extent is approximately $\mathrm{z}=-65 \AA$ to $+65 \AA$ with saline solution occupying region from $z=-240 \AA$ to $+240 \AA$. Upon attaining quasisteady state, the brush collapses to span approximately $z=-50 \AA$ to $+50 \AA$. (b) System shows ions ( $\mathrm{Cl}$ - is Cyan and $\mathrm{K}^{+}$is Brown) on the left and water molecules on the right. The four large red spheres represent the oxygen at the glycosidic bonds at the center of the heparin that are tethered.

Simulations were conducted for different length hyaluronic acid brushes and GAG brushes in 260 to $280 \mathrm{mM} \mathrm{NaCl}$ or $\mathrm{KCl}$ solutions. Detailed information about each system are shown in Table S1a. We first showed that all-atom MD simulations of hyaluronic acid brush can produce consistent brush electroneutrality with anion exclusion using both CHARMM additive all-atom carbohydrate force field ${ }^{30-33}$ and CHARMM-Drude polarizable force field for glycosidic linkages. ${ }^{34}$ The effect of pair-specific Lennard-Jones parameters (referred to as nonbonded fix or NBFIX) on the Donnan potential, dielectric constant, and the topology of the GAG brush were evaluated for $\mathrm{Na}^{+}$and $\mathrm{K}^{+}$interactions with carboxylate and sulfate anions in the GAGs. ${ }^{35}$ 
Molecular Dynamics Setup: The heparin and hyaluronic acid glycan models were prepared from CHARMM-GUI module "Glycan Reader \& Modeler" respectively. ${ }^{36-39}$ All simulations with nonpolarizable force fields were executed in GROMACS (version 2016.4) ${ }^{40}$ with CHARMM TIP3P water ${ }^{41}$ in conjunction with CHARMM additive carbohydrate force field. Each system was solvated with total salt of $200 \mathrm{mM}$ of $\mathrm{KCl}$ or $\mathrm{NaCl}$ in the simulation box.

The components of the simulations are summarized in Table S1. Coulomb interactions were calculated using the particle-mesh Ewald (PME) algorithm ${ }^{42}$ using the VMD PMEPot plugin. ${ }^{43}$. All electrostatic potentials in this study were calculated to provide a 3D electrostatic potential map $\phi(\mathrm{r})$ based on the selected charged atoms in the simulated system $\rho_{\mathrm{i}}(\mathrm{r})$ by solving $\nabla^{2} \varphi(r)=$ $-4 \pi \sum_{i} \rho_{i}(r)$ on a $1 \AA$ resolution grid. Simulations were performed both with and without Nonbonded FIX (NBFIX) corrections for the $\mathrm{K}^{+} / \mathrm{COO}^{-}$and $\mathrm{K}^{+} / \mathrm{OSO}_{3}{ }^{-}$ion pairs. These modified Lennard-Jones parameters were previously optimized by $\mathrm{Yoo}$ and Aksimentiev ${ }^{35}$ using osmotic pressure simulations developed by Luo and Roux ${ }^{38}$ for cation-acetate and cation-phosphate in crowded aqueous salt solutions. Note the phosphate terminal oxygen has the same nonbonded parameters as sulfate terminal oxygen in CHARMM36 force field. Simulation of $\mathrm{Na}^{+} / \mathrm{COO}$ - and $\mathrm{Na}^{+} / \mathrm{OSO}_{3}{ }^{-}$ion pairs utilized the CHARMM36 force field default parameters that included the NBFIX corrections from osmotic pressure data on sodium acetate and electrophoresis data on lipid vesicles. ${ }^{44}$ As an initial assessment of the role of polarization, the hyaluronic acid system was also simulated using CHARMM program version $44 \mathrm{~b} 2$ and with the optimized Drude polarizable force field to simulate polysaccharides containing furanoses and pyranoses ${ }^{34}$. The default NBFIX corrections for Drude $\mathrm{Na}^{+} / \mathrm{COO}^{-}$and $\mathrm{K}^{+} / \mathrm{COO}^{-}$ion pairs have also been optimized using osmotic pressure calculations and included in current simulations.

\section{RESULTS AND DISCUSSION}

Charge density and length of brushes. Heparin lengths of 6, 10, 12, 14 and 16 disaccharide units were simulated with $\mathrm{NaCl}$ for $100 \mathrm{~ns}$ in NVT ensemble with constant volume for the simulation box (Table S1a System II), and the charge density profile of the GAGs was observed to be quite non-uniform for the shorter lengths while the longer 12 and 16 disaccharide brushes approached nearly a uniform charge density of about $3 \mathrm{M}$ with superimposed oscillations associated with the disaccharide units (Figure S1). For each of the brush length, the number of chloride ions is fixed at 93 over the entire volume to provide $0.20 \mathrm{M}$. However, since these co-ions are excluded from the brush the actual concentration outside the brush increases with brush length reaching 0.26-0.28 $\mathrm{M}$ for the 16 disaccharide unit brushes presented here.

The brushes were observed to collapse to a statistically-invariant thickness within 50ns, hence we chose 100ns and 16 disaccharides as sufficient in temporal and spatial extent that the internal brush structure could be characterized as quasi-steady and near-uniform. An example of a charge density profile along the z-axis (x-y averaged) for 16-disaccharide heparin in $0.26 \mathrm{M} \mathrm{KCl}$ (Table S1a System I) is shown in Figure 3. Although the simulated system is maintained as electroneutral and 
$\sim 3 \mathrm{M}$ potassium nearly cancels the negative GAG charge in the brush, there are small variations of net charge density in the brush that are less than $10 \%$ of the anionic brush charge density as seen by the gold curve. The bumps at the brush edges in the gold curve show a double-double layer of positive charge just outside of the brush and negative charge just inside the brush that is expected under diffuse-layer Boltzmann partitioning.

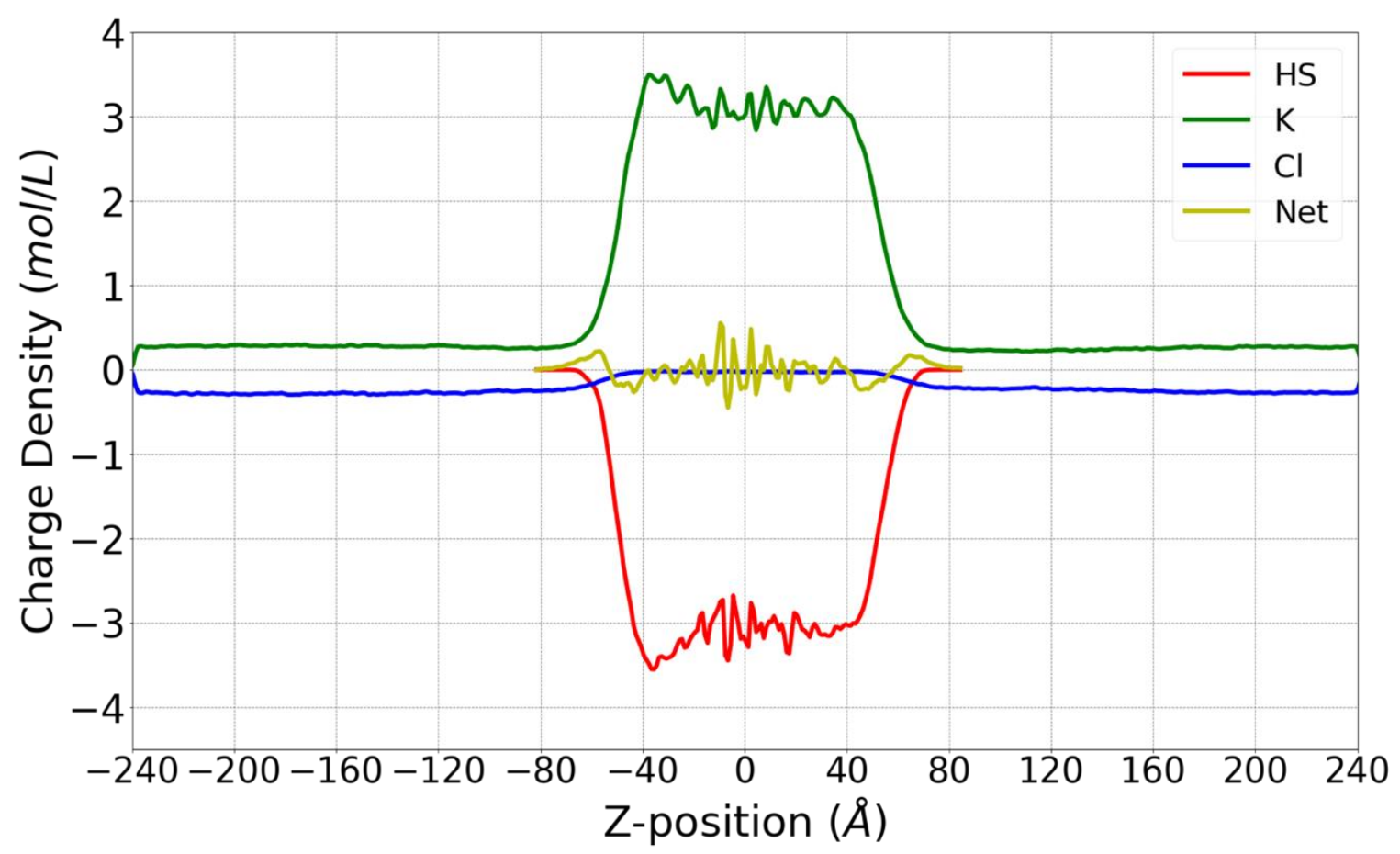

Figure 3. The quasi-steady charge density profile of heparin in $0.26 \mathrm{M} \mathrm{KCl}$, calculated using VMD VolMap function averaged over 100ns simulation.

A summary of the GAG Brush simulation results is presented in Table 1 which documents the brush-collapse by thickness and density as well as the bulk salt concentration that results upon coion exclusion. The polymer length is defined as the distance between the brush-edges averaged over the final 30ns of simulation and brush-edges are defined as the locations where the negative GAG charge-density value is equal to the average of the maximum and minimum values across the entire domain. 
Table 1. Results of GAG Brush Simulations after 100ns AA simulations.

\begin{tabular}{|c|c|c|c|c|c|c|c|c|}
\hline GAG & Salt & $\begin{array}{c}\text { Bulk } \\
\text { Salt } \\
\text { Conc. } \\
(\mathrm{M})\end{array}$ & $\begin{array}{c}\text { GAG } \\
\text { charge } \\
(\mathrm{M})\end{array}$ & $\begin{array}{c}\text { GAG } \\
\text { Mass } \\
(\text { Dalton })\end{array}$ & $\begin{array}{c}\text { Polymer } \\
\text { Length } \\
(\AA)\end{array}$ & $\begin{array}{c}\text { Initial } \\
\text { Polymer } \\
(\AA)\end{array}$ & $\begin{array}{c}\text { Polymer } \\
\text { Length } \\
\text { Fraction }\end{array}$ & $\begin{array}{c}\text { Brush } \\
\text { Density } \\
(\mathrm{g} / \mathrm{L})\end{array}$ \\
\hline Hyaluronan & $\mathrm{NaCl}$ & 0.28 & 0.51 & 6071.05 & 129.7 & 157.8 & 0.82 & 194.32 \\
\cline { 2 - 10 } & $\mathrm{KCl}$ & 0.28 & 0.49 & 6071.05 & 135.8 & 160.3 & 0.85 & 185.59 \\
\hline Heparin & $\mathrm{NaCl}$ & 0.27 & 2.78 & 10457.66 & 119.3 & 145.1 & 0.82 & 363.90 \\
\cline { 2 - 9 } & $\mathrm{KCl}$ & 0.26 & 2.93 & 10457.66 & 113.2 & 146.0 & 0.78 & 383.51 \\
\hline
\end{tabular}

*polymer lengths were averaged over last $30 \mathrm{~ns}$ in each system.

Donnan potential. We then calculated electrostatic potential for the various combinations of salt with 16-disaccharide GAGs using different force fields (Table S1b). The results of the electrostatic potential were computed using VMD PMEPot plugin $^{43}$ and convergence over time was monitored (Figure S4). Averaged potential profiles are presented in Figure 4 for the hyaluronan- $\mathrm{KCl}$ case. In contrast to the near-uniform brush charge of Figure 3, this electrostatic distribution is not as smooth and is a result of the composite summing of electric potential contributions from all ion charges and all partial-charges associated with GAG atoms and water partial charges. Nonetheless, a consistent result is that the brush region holds a positive potential relative to the bulk salt solution.

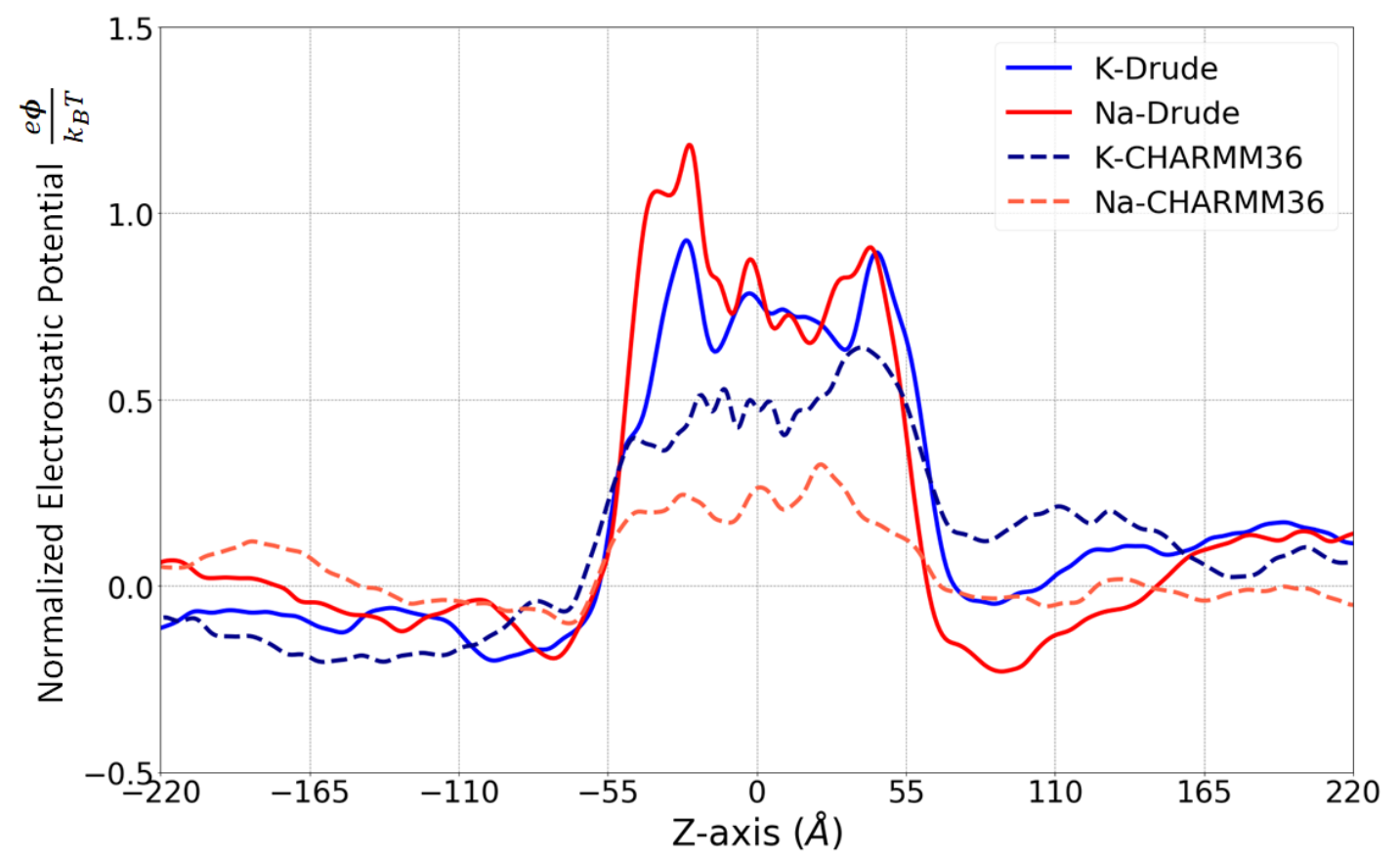


Figure 4: Hyaluronan-Potassium Brush Particle Mesh Ewald (PME) electrostatic potential for non-polarizable CHARMM (new NBFIX for $\mathrm{K}^{+} / \mathrm{COO}^{-}$and $\mathrm{K}^{+} / \mathrm{OSO}_{3}{ }^{-}$, and $\mathrm{CHARMM} 36 \mathrm{NBFIX}$ for $\mathrm{Na}^{+} / \mathrm{COO}^{-}$and $\mathrm{Na}^{+} / \mathrm{OSO}_{3}$ ) and polarizable Drude-model simulations. Curves are shifted to provide average of zero/ground baseline outside of the brush. (i.e. defined as the region where the net potential is less than the half-maximum difference between the net potential peak and its minimum).

Surprisingly, the Donnan rule does not apply; even though the brush excludes all anions and the net brush charge is neutralized by cations, the net electrostatic potential is positive relative to the surrounding saline solution. We quantify the effective brush potential for all conditions and the results are reported in column 4 of Table 2. In the case of the dashed blue curve of Figure 4 for HA- $\mathrm{K}^{+}$using the CHARMM method, the average potential is $0.44 \pm 0.03$ where the standard deviation is the temporal variation of the spatial average for three time points 40, 80, and 100ns. Therefore, the net relative brush potential corresponds to positive $11.7 \pm 0.8 \mathrm{mV}$ for the thermal voltage of $26.7 \mathrm{mV}$ (at temperature of $310.15 \mathrm{~K}$ ).

Perhaps these inverted Donnan potentials in GAG brushes should not be surprising. Similar effects are observed in colloidal systems and nanoscale solid-liquid interfaces where water confinement and dispersion forces become important. ${ }^{45-49}$ The behavior of water in crowded environments is indeed quite different than bulk water. Fundamental spectroscopic studies combined with MD simulations have recently elucidated the nature of slow-water in crowded environments. ${ }^{50-55}$ Not only do water dielectric decrements appear around charged groups and ions, but ion hydration effects also control ion-pairing that also affects the electrostatics. ${ }^{56,57}$

Is the inverted electrostatic potential an artifact of the all-atom partial charge model in CHARMM? We explored this question by using both non-polarizable and polarizable force field models in our simulations. Optimization of nonpolarizable force fields in MD is a topic of considerable active research where various ionic charge scaling electronic continuum correction (ECC) models as well as adjustments of LJ parameters between specific ion-pairs using nonbonded fix (NBFIX) models have been developed, in part to address excessive ion-pairing that has been observed in some MD simulations. ${ }^{58-60}$ The CHARMM36 force field used in the current study includes NBFIX terms that reproduce experimental osmotic pressure of $\mathrm{NaCl}, \mathrm{KCl}$, and sodium acetate up to 3 to $5 \mathrm{M}$ concentrations. ${ }^{35}$ To assess the possible influence of polarizability on Donnan potential, we simulated the hyaluronan-potassium system using a recently-developed CHARMM Drude polarizable model for carbohydrates. Interestingly, including polarizability produced similar inverted Donnan potentials with even larger magnitudes as shown in Figure 4. Therefore, our quantitative results are indeed dependent on the model but the inversion of the electrostatic potential of the brush did not change. We note that the effect is more pronounced for potassium than for sodium cations and a negative Donnan potential is still observed for our System II sodium-heparin brush. The presence of a positive brush potential appears to correlate with the relative prevalence of CIP cations as there is a substantially higher CIP fraction observed for $\mathrm{K}^{+}$ than $\mathrm{Na}^{+}$(Note the small areas under the curves for SIP in Figure S2b versus S2a). 
Dielectric Decrement. We computed the dielectric constant of the water for each brush simulation using the following equation for the relative permittivity $\varepsilon$ given the permittivity of vacuum $\varepsilon_{0}$, Boltzmann constant $\mathrm{k}_{\mathrm{B}}$, temperature $\mathrm{T}$, and dipole moment $\mathrm{M}$ of the water molecules within the available volume $\mathrm{V}$.

$$
\varepsilon=1+\frac{\left\langle M^{2}\right\rangle-\langle M\rangle^{2}}{3 \varepsilon_{o} V k_{B} T}
$$

The dielectric constant for the four GAG simulations are shown as a function of the distance from the center of the brush in Figure 5. The dielectric constant for the hyaluronan cases is observed to fall from around 70 outside the brush to under 50 within the brush. Similarly, for heparin, the constant falls from around 60 to a minimum around 35 within the brush. The fact that our solution phase exhibits a lower dielectric constant than bulk water is expected due to the high salt content as well as the temperature of $310.15 \mathrm{~K}$.

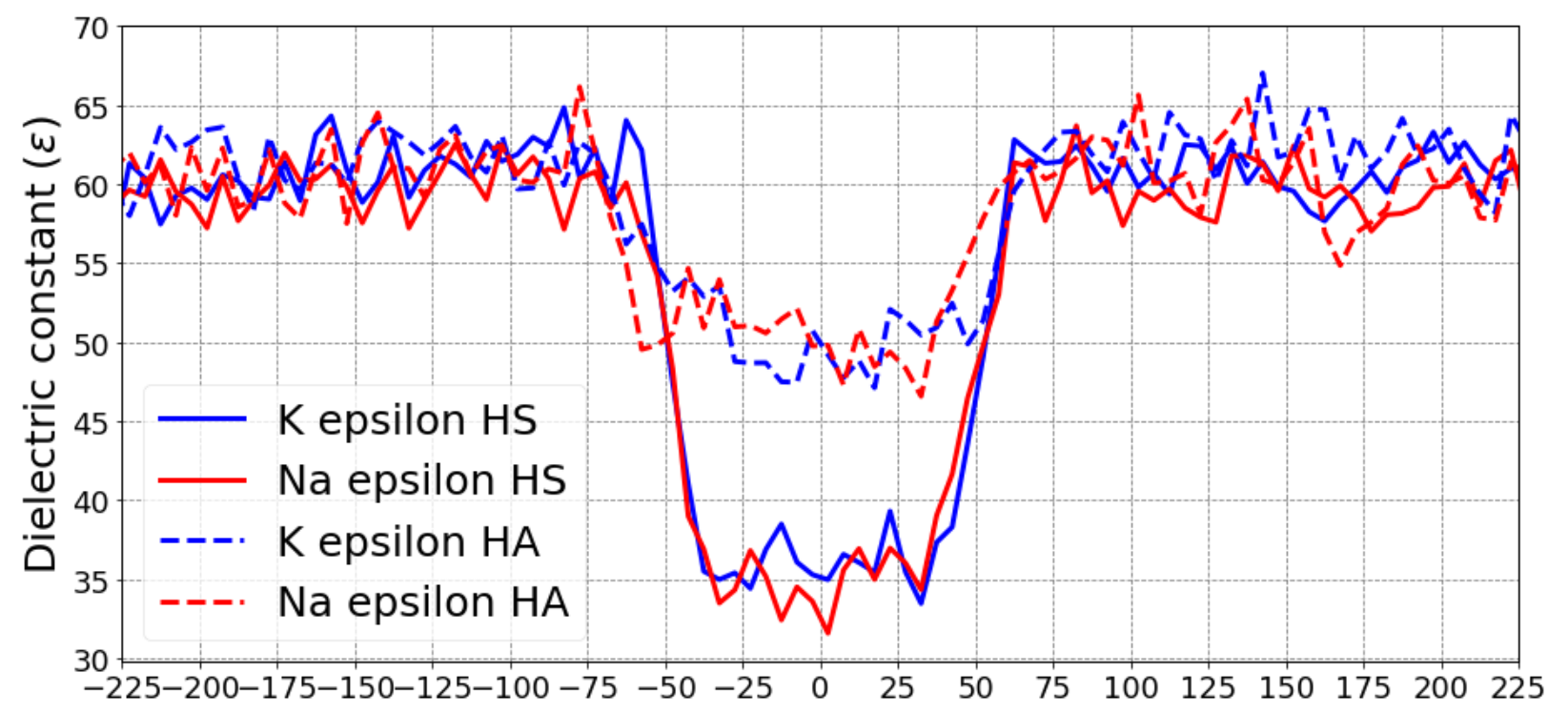

Figure 5. Dielectric constant within $10 \AA$ length slabs in the z-direction averaged over the $40 \AA \mathrm{x}$ $40 \AA$ x-y domain; smoothed over $\sim 2$ disaccharides using a $20 \AA$ uniform window.

Ion pairing. The high charge densities result in substantial ion pairing in the form of contact ion pairs (CIP) and solvent separated ion pairs (SIP) ${ }^{61,62}$ As a first approximation, one might consider ion-pairing to fixed charged GAGs to provide a neutral pair such that the brush Donnan potential would be determined by the free ions in the brush that would be Boltzmann-partitioned from the bulk solution. This type of Donnan rule has long been applied in brush models with ionizable charged groups to consider $\mathrm{pH}$ effects under the assumption that free hydronium is Boltzmannpartitioned..$^{20-22,26,63}$ In our simulations, the use of physiological $\mathrm{pH}$ and salt concentration values imply million-fold fewer hydronium than salt ions; so hydronium is not present in our MD simulations. 
Radial distribution functions (RDF) of the cation-anion interactions typically display two peaks corresponding to the large CIP and SIP ion pair populations and the well corresponding to an energy barrier between them. Figure 6 presents the RDF plots for the cations as they pair with the oxygen atoms associated with sulfates and carboxylates using the CHARMM36 with NBFIX. For $\mathrm{K}^{+}$pairing, CIP occurs for separation between the oxygens of less than about $3.4 \AA$ while SIP occurs for separation between $3.4 \AA$ and $5.9 \AA$. Similarly, for $\mathrm{Na}+$ pairing with these oxygen atoms, CIP occurs for separation between the oxygens of less than about $3.1 \AA$ while SIP occurs for separation between $3.1 \AA$ and $5.5 \AA$. These results are consistent with the models of ion-pairing described by Marcus and Collins that are associated with negative free energy of binding driven by entropic gain of released water when similarly-hydrated ions pair. ${ }^{61,64,65}$

Another important feature seen in Figure 6 is that cation-pairing to both GAG carboxylate oxygens and sulfate oxygens of heparin are present in CIP and SIP forms in similar quantity. In other words, the area under the curves for CIP and SIP forms are quite similar for all pairings. Finally, we note that the 3-O-sulfates and 6-O-sulfates show more CIP pairing than the 2-O-sulfates for both potassium and sodium; which could play a role in the distinct regulatory roles that heparin and sulfotransferases play in biology. ${ }^{66,67}$ A more customary treatment of RDFs based on the central carbon atom of the carboxylate or sulfate is shown in Figure S2 where the ion-specific behavior is quite clear. In Figure S3, a direct comparison of the RDFs of hyaluronan carboxylate-cation pairing to the central carbon and the oxygen atoms are shown and sodium is observed to have a higher SIP/CIP ratio than potassium. It was also observed (Figure S5) that without the NBFIX correction for $\mathrm{K}+$ and sulfate, there was substantial overbinding and an even more positive Donnan potential in the brush.
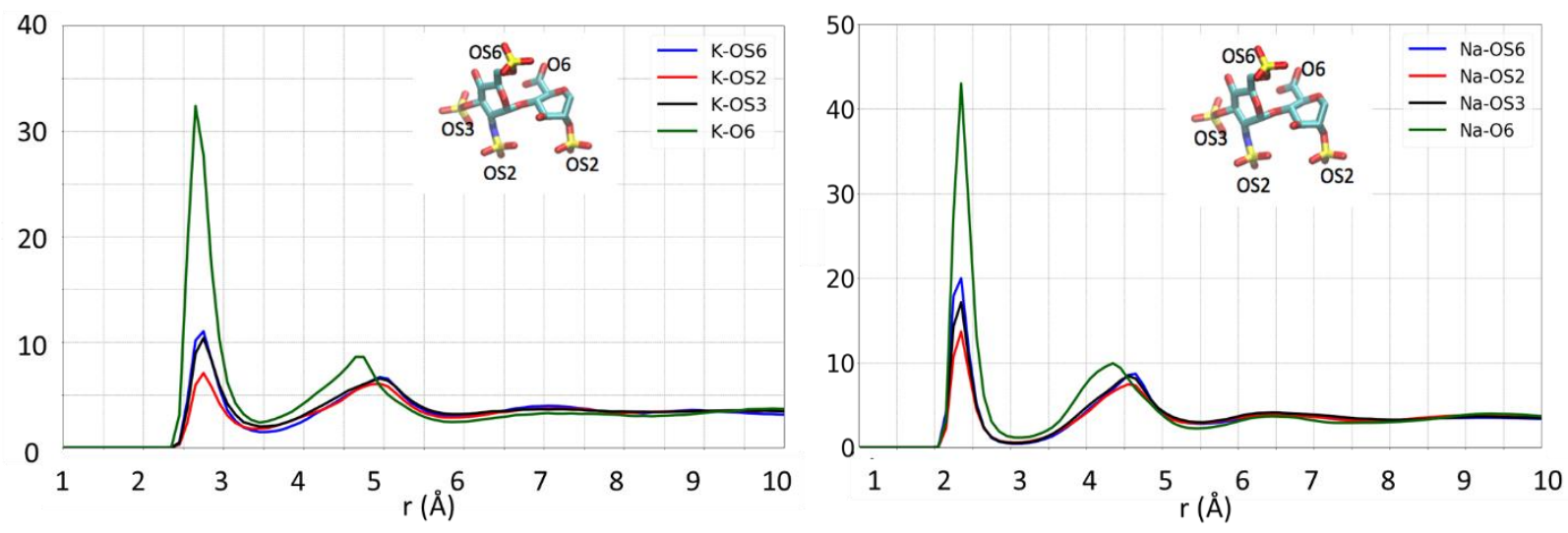

Figure 6. Radial distribution functions (RDF) of cation ions $\mathrm{K}^{+} / \mathrm{Na}^{+}$with sulfate oxygen and carboxyl oxygen in heparin systems. RDF curves were calculated from System I and II (CHARMM36 force field) for ion pairs of $\mathrm{K}^{+} / \mathrm{COO}^{-}$(new NBFIX), $\mathrm{K}^{+} / \mathrm{OSO}_{3}{ }^{-}$(new NBFIX), $\mathrm{Na}^{+} / \mathrm{COO}^{-}(\mathrm{CHARMM} 36 \mathrm{NBFIX})$, and $\mathrm{Na}^{+} / \mathrm{OSO}_{3}{ }^{-}$(CHARMM36 NBFIX). See NBFIX values in Table S2. 
These ion pairing results might suggest that modelling of CIP and SIP populations could directly apply the Eigen-Tamm law of mass action kinetics. ${ }^{68}$ However, this approach is complicated by the fact that many ions are shared by multiple counterions, making the definition of concentrations ambiguous. This effect is clearly seen in Figure 7 where snapshots of two potassium ions near the heparin brush are shown. The intra-molecularly shared potassium ion shown on the left figure is seen to be within CIP distance of three sulfate oxygens $(2.79,2.89$ and $2.66 \AA)$ and within SIP distance of another sulfate oxygen. Similarly, the inter-molecularly shared potassium shown on the right figure is seen to be within CIP distance of one carboxylate oxygen $(2.63 \AA)$ and one sulfate oxygen $(2.71 \AA)$.
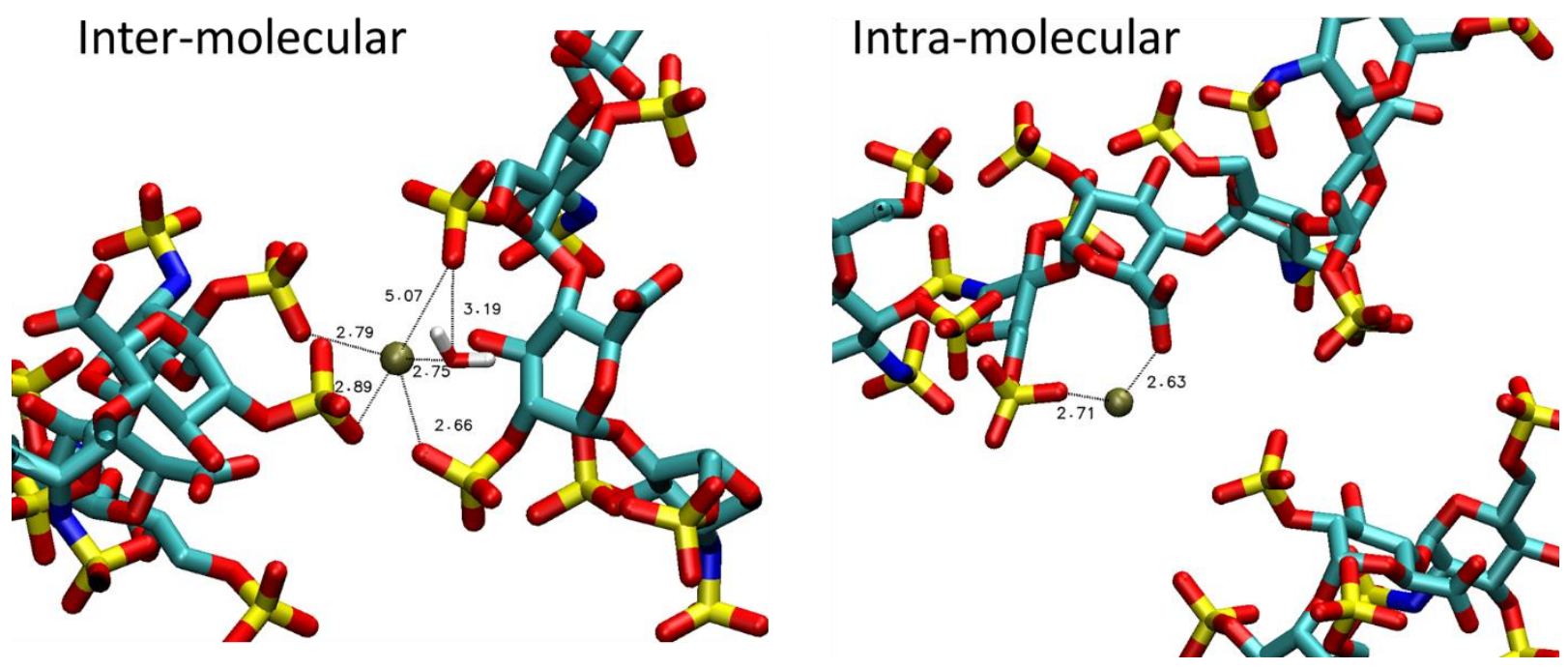

Figure 7: Ion-pairing in crowded GAG brush. Snapshot images of potassium ion-pairing to heparin (CHARMM force field for $\mathrm{K}^{+} / \mathrm{COO}^{-}$(new NBFIX) and $\mathrm{K}^{+} / \mathrm{OSO}_{3}{ }^{-}$(new NBFIX)). Simultaneous contact- and solvent-separated ion pairing to sulfate oxygens (left) and simultaneous pairing to carboxylate oxygen and sulfate oxygen (right).

Relation with mean-field theory. A principal aim of this study is to characterize emergent behavior of GAG brushes to support microscale mean-field modeling through understanding of the equilibrium biophysics of the brushes. We observe both ion-pairing and dielectric decrement such that the equilibrium attained across the brush-solution interface can be represented by generalized Boltzmann partitioning that includes ion Born-solvation energy associated with the dielectric decrement, as well as the ion-pairing energies of cations with anionic brush charges. Minimization of free energy, or equivalently, integration of a steady-state Born-modified PoissonNernst-Planck (PNP) model with ion-pair binding yield such a generalized Boltzmann distribution as follows. ${ }^{48,69,70}$ 


$$
c_{i, b}=c_{i, o} \exp \left\{-\frac{W_{i}}{k_{B} T}\right\}=c_{i, o} \exp \left\{-\frac{q_{i} \varphi_{b}}{k_{B} T}-\frac{-\Delta G_{i}^{S}}{k_{B} T} \frac{\epsilon_{w}}{\epsilon_{w}-1}\left[\frac{1}{\epsilon_{b}}-\frac{1}{\epsilon_{o}}\right]-\frac{\Delta \mu_{i}}{k_{B} T}\right\}
$$

The three terms represent the contributions of work done in partitioning of ion $i$ from the solution phase represented by the $o$ subscript, to the brush represented by the $b$ subscript, due to electric potential, Born hydration, and ion-pairing, respectively. The electrostatic partitioning represents the ion charge $q_{i}$ in brush potential $\varphi_{b}$ relative to the solution phase using the simulation results for PME potential. In the absence of any dielectric decrement or ion-pairing, the brush potential could be considered to be the Donnan potential. The Born hydration term is based on the dilute experimental hydration energy of the ion $\Delta G_{\mathrm{i}}$ s where the dielectric constant of water is $\varepsilon$ and the subscript $w$ indicates the dilute value and the low value in the brush causes the ion to prefer to partition out of the brush into the higher dielectric water. The final term is the excess chemical potential difference $\Delta \mu_{i}$ across the interface that represents the ion-pair binding free energy and any ion-GAG interactions not associated with ion pairing. Ion-pair RDFs have been generated using MD and the relationship to Eigen-Tamm binding constants is described by Fennel et al. ${ }^{71}$ for ion pairs and by Chen and Pappu ${ }^{72}$ for clusters of up to 6 ions.

In Table 2, we report average values of these three energy terms from our GAG brush simulations. Column 3 contains values of the total partitioning energy that is required to attain electroneutrality in the brush and is equivalent to the naïve dimensionless Donnan potential that would be the electrostatic potential in the brush if the partitioning was entirely due to the balance of electrophoresis and diffusion. The fourth and fifth columns show the non-negative electrostatic potential energy and the positive Born hydration energy. The Born hydration energy is computed using the experimental hydration free energies $\Delta G_{\mathrm{Na}}{ }^{\mathrm{s}}=-424 \mathrm{~kJ} / \mathrm{mol}$ and $\Delta G_{\mathrm{K}}{ }^{\mathrm{s}}=-352 \mathrm{~kJ} / \mathrm{mol}$. The cation binding free energy is computed as the residual required to satisfy the energy balance of the equation above and is shown in the final column. We see that both electrostatic and hydration effects tend to repel cations and that the excess energy required to overcome these effects and attain electroneutrality is the substantial negative binding energies of ion-pairing. We observe that in contrast to our initial expectations, the electrostatic potential contributes the least energy to the cation partition energy.

Table 2. Energy contributions to cation partitioning after 100ns AA simulations.

\begin{tabular}{|c|c|c|c|c|c|c|c|}
\hline GAG & Salt & $\begin{array}{c}\text { Total } \\
\text { Partitioning } \\
\text { Energy of } \\
\text { Cation }\end{array}$ & $\begin{array}{c}\text { PME Brush } \\
\text { Potential } \\
\text { Energy }\end{array}$ & $\begin{array}{c}\text { Cation Born Energy } \\
q_{t} \varphi_{b}\end{array}$ & $\begin{array}{c}\text { Brush } \mathrm{H}_{2} \mathrm{O} \\
\text { Dielectric } \\
\text { Constant }\end{array}$ & $\begin{array}{c}\text { Solution } \mathrm{H} 2 \mathrm{O} \\
\text { Dielectric } \\
\text { Constant }\end{array}$ & $\begin{array}{c}\text { Cation } \\
\text { Binding } \\
\text { Energy }\end{array}$ \\
& $\frac{W_{i}}{k_{B} T}$ & $\frac{-\Delta G_{i}^{S}}{k_{B} T}$ & $\frac{\epsilon_{w}}{k_{B} T}\left[\frac{1}{\epsilon_{b}}-\frac{1}{\epsilon_{o}}\right]$ & $\epsilon_{b}$ & $\epsilon_{o}$ & $\frac{\Delta \mu_{i}}{k_{B} T}$ \\
\hline Hyaluronan & $\mathrm{NaCl}$ & -0.62 & $0.17 \pm 0.06$ & $0.53 \pm 0.2$ & $50.7 \pm 2.1$ & $60.4 \pm 2.5$ & $-1.32 \pm 0.2$ \\
\hline
\end{tabular}




\begin{tabular}{|c|c|c|c|c|c|c|c|}
\hline & $\mathrm{KCl}$ & -0.56 & $0.44 \pm 0.03$ & $0.46 \pm 0.2$ & $51.2 \pm 2.9$ & $61.8 \pm 1.9$ & $-1.46 \pm 0.2$ \\
\hline Heparin & $\mathrm{NaCl}$ & -2.34 & $-0.62 \pm 0.27$ & $1.62 \pm 0.6$ & $37.5 \pm 4.7$ & $59.1 \pm 2.6$ & $-3.35 \pm 0.6$ \\
\cline { 2 - 7 } & $\mathrm{KCl}$ & -2.41 & $0.96 \pm 0.14$ & $1.36 \pm 0.5$ & $37.9 \pm 4.2$ & $60.5 \pm 2.1$ & $-4.73 \pm 0.5$ \\
\hline
\end{tabular}

*The standard deviations for PME Brush Potential energy were calculated over 40ns,80ns, 100ns for each system. The standard deviations for brush $\mathrm{H}_{2} \mathrm{O}$ and solution $\mathrm{H}_{2} \mathrm{O}$ dielectric constants were computed over the corresponding z-axis region, respectively. The cation binding energy and total partition standard deviation followed the rule of propagation of uncertainty.

Finally, we consider the magnitude of the cation binding energies reported in the final column of Table 2. Note that the magnitude of the binding energy appears to correlate with the number of anionic charges per disaccharide unit. If the binding is dominated by ion-pairing, the hyaluronan cation binding energy can be identified as the net cation-carboxylate binding energy that yields

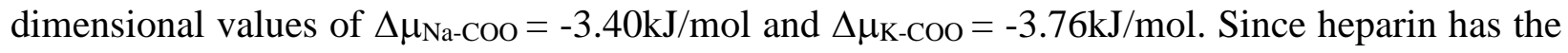
same carboxylate content as hyaluronan, in the absence of cooperativity of binding, the cationheparin binding energy can be estimated as comprising $1 / 5$ carboxylate binding energy and 4/5 sulfate binding energy. Here, the assumption is also made that the cation-sulfate binding energy is the same regardless of the sulfate glycan site, O-sulfation, or $\mathrm{N}$-sulfation. Using this approach to solve for the average cation-sulfate binding energy, the ion-pair binding energies are presented in Table 3. Further evidence that ion-pairing dominates the binding is provided by simulations of hyaluronan with neutralized GAG anions as shown in Table S1a systems V and VI. The result is that chloride anions are no longer excluded from the brush and the PME potential is negligible.

Table 3. Approximate ion pair binding energy.

\begin{tabular}{|c|c|c|}
\hline$\Delta \mu(\mathrm{kJ} / \mathrm{mol})$ & $\mathrm{COO}^{-}$ & $\mathrm{SO}_{4}^{-}$ \\
\hline $\mathrm{Na}^{+}$ & $-3.40 \pm 0.3$ & $-1.31 \pm 1.0$ \\
\hline $\mathrm{K}^{+}$ & $-3.76 \pm 0.3$ & $-2.11 \pm 0.8$ \\
\hline
\end{tabular}

These results are consistent with the trends observed in the RDFs showing that carboxylates bind the cations more strongly than the sulfates. Attempts to develop more quantitative stoichiometric binding models using effective dissociation constants in an Eigen-Tamm kinetic framework face challenges due to cluster formation that prevents identification of unique populations of CIP, SIP, and SSIP pairing. Incorporation of such a multi-step kinetic modeling approach to accommodate the clusters is described by Chen and $\mathrm{Pappu}^{72}$. 


\section{CONCLUSIONS}

The results of the all atom MD simulations of GAG brushes presented here show ion-specific behavior with energy contributions associated with Born-hydration, electrostatic, and ion-pair binding energies that are of similar magnitude. The results demonstrate that sulfates bind to $\mathrm{Na}^{+}$ and $\mathrm{K}^{+}$approximately half as tightly as carboxylates, but heparin with $4 \mathrm{x}$ the number of sulfates as carboxylates results in ion binding that is dependent on the multivalent integral charge density with minimal cooperativity of the binding. Furthermore, the radial distribution functions of ionpairing show similar abundance of CIP and SIP forms for all combinations of cations and GAG anions. Our results suggest that mean-field models require inclusion of both ion-pair binding energy and Born hydration using water dielectric constant variation that varies in space and time. We would expect that such a model could describe emergent brush biophysics on length scales substantially larger than the Debye length. Thus, modified Poisson-Boltzmann models including local ion-pairing through law of mass action could be used for quasi-equilibria ${ }^{26,56}$; and Poisson's equation of electrostatics coupled with Nernst-Planck (PNP) models of transport of ions due to electrophoresis and diffusion, and bimolecular Eigen-Tamm ion-pairing reactions might be used to describe transient MD results. ${ }^{61,62,68,72}$ The balances and tradeoffs of electrostatic, ion-binding, and Born-hydration energy terms could have important implications for both in vitro and in vivo systems that apply to electrophysiology, tissue engineering, separation science, therapeutics and medical device engineering.

\section{AUTHOR INFORMATION}

The authors declare no competing financial interests.

\section{ACKNOWLEDGMENT}

J.D.S acknowledges support from the Keck Graduate Institute faculty research fund and Y.L.L. acknowledges the support from NIH Grant R01-GM130834. Computational resources were provided via the Extreme Science and Engineering Discovery Environment (XSEDE) allocation TG-MCB160119, which is supported by NSF grant number ACI-154862. The authors acknowledge very helpful conversations with Prof. Ali Nadim and Dr. Shenda Baker regarding the biophysical and polymer science aspects of this work and thank the Prof. Alex MacKerell group, in particular Dr. Asaminew Haile Aytenfisu for assistance with the Drude model and Prof. Justin Lemkul for discussions regarding the NBFIX parameters in the Drude model. 


\section{REFERENCES}

(1) Minsky, B. B.; Dubin, P. L.; Kaltashov, I. A. Electrostatic Forces as Dominant Interactions Between Proteins and Polyanions: An ESI MS Study of Fibroblast Growth Factor Binding to Heparin Oligomers. J. Am. Soc. Mass Spectrom. 2017, 28 (4), 758-767. https://doi.org/10.1007/s13361-017-1596-0.

(2) Zimmermann, R.; Werner, C.; Sterling, J. Exploring Structure-Property Relationships of GAGs to Tailor ECM-Mimicking Hydrogels. Polymers 2018, 10 (12), 1376. https://doi.org/10.3390/polym10121376.

(3) Freudenberg, U.; Atallah, P.; Limasale, Y. D. P.; Werner, C. Charge-Tuning of Glycosaminoglycan-Based Hydrogels to Program Cytokine Sequestration. Faraday Discuss. 2019, 219 (0), 244-251. https://doi.org/10.1039/C9FD00016J.

(4) Chiodelli, P.; Bugatti, A.; Urbinati, C.; Rusnati, M. Heparin/Heparan Sulfate Proteoglycans Glycomic Interactome in Angiogenesis: Biological Implications and Therapeutical Use. Molecules 2015, 20 (4), 6342-6388. https://doi.org/10.3390/molecules20046342.

(5) Farrugia, B. L.; Lord, M. S.; Melrose, J.; Whitelock, J. M. The Role of Heparan Sulfate in Inflammation, and the Development of Biomimetics as Anti-Inflammatory Strategies: Journal of Histochemistry \& Cytochemistry 2018.

https://doi.org/10.1369/0022155417740881.

(6) Collins, L. E.; Troeberg, L. Heparan Sulfate as a Regulator of Inflammation and Immunity. Journal of Leukocyte Biology 2019, 105 (1), 81-92. https://doi.org/10.1002/JLB.3RU0618246R.

(7) Verdurmen, W. P. R.; Wallbrecher, R.; Schmidt, S.; Eilander, J.; Bovee-Geurts, P.; Fanghänel, S.; Bürck, J.; Wadhwani, P.; Ulrich, A. S.; Brock, R. Cell Surface Clustering of Heparan Sulfate Proteoglycans by Amphipathic Cell-Penetrating Peptides Does Not Contribute to Uptake. Journal of Controlled Release 2013, 170 (1), 83-91.

https://doi.org/10.1016/j.jconrel.2013.05.001.

(8) Dam, T. K.; Brewer, F. C. Maintenance of Cell Surface Glycan Density by Lectin-Glycan Interactions: A Homeostatic and Innate Immune Regulatory Mechanism. Glycobiology 2010, 20 (9), 1061-1064. https://doi.org/10.1093/glycob/cwq084.

(9) $\mathrm{Xu}, \mathrm{D}$; Esko, J. D. Demystifying Heparan Sulfate-Protein Interactions. Annu. Rev. Biochem. 2014, 83, 129-157. https://doi.org/10.1146/annurev-biochem-060713-035314.

(10) Weiss, R. J.; Esko, J. D.; Tor, Y. Targeting Heparin- and Heparan Sulfate-Protein Interactions. Org Biomol Chem 2017, 15 (27), 5656-5668.

https://doi.org/10.1039/c7ob01058c.

(11) Ori, A.; Wilkinson, M. C.; Fernig, D. G. A Systems Biology Approach for the Investigation of the Heparin/Heparan Sulfate Interactome. J Biol Chem 2011, 286 (22), 19892-19904. https://doi.org/10.1074/jbc.M111.228114.

(12) Bolten, S. N.; Rinas, U.; Scheper, T. Heparin: Role in Protein Purification and Substitution with Animal-Component Free Material. Appl Microbiol Biotechnol 2018, 102 (20), 86478660. https://doi.org/10.1007/s00253-018-9263-3. 
(13) Xiong, S.; Zhang, L.; He, Q.-Y. Fractionation of Proteins by Heparin Chromatography. Methods Mol. Biol. 2008, 424, 213-221. https://doi.org/10.1007/978-1-60327-064-9_18.

(14) Rauch, J. N.; Chen, J. J.; Sorum, A. W.; Miller, G. M.; Sharf, T.; See, S. K.; Hsieh-Wilson, L. C.; Kampmann, M.; Kosik, K. S. Tau Internalization Is Regulated by 6-O Sulfation on Heparan Sulfate Proteoglycans (HSPGs). Sci Rep 2018, 8. https://doi.org/10.1038/s41598018-24904-z.

(15) Stopschinski, B. E.; Holmes, B. B.; Miller, G. M.; Manon, V. A.; Vaquer-Alicea, J.; Prueitt, W. L.; Hsieh-Wilson, L. C.; Diamond, M. I. Specific Glycosaminoglycan Chain Length and Sulfation Patterns Are Required for Cell Uptake of Tau versus $\alpha$-Synuclein and $\beta$-Amyloid Aggregates. J. Biol. Chem. 2018, 293 (27), 10826-10840.

https://doi.org/10.1074/jbc.RA117.000378.

(16) Mycroft-West, C. J.; Su, D.; Pagani, I.; Rudd, T. R.; Elli, S.; Guimond, S. E.; Miller, G.; Meneghetti, M. C. Z.; Nader, H. B.; Li, Y.; Nunes, Q. M.; Procter, P.; Mancini, N.; Clementi, M.; Bisio, A.; Forsyth, N. R.; Turnbull, J. E.; Guerrini, M.; Fernig, D. G.; Vicenzi, E.; Yates, E. A.; Lima, M. A.; Skidmore, M. A. Heparin Inhibits Cellular Invasion by SARSCoV-2: Structural Dependence of the Interaction of the Surface Protein (Spike) S1 Receptor Binding Domain with Heparin. bioRxiv 2020, 2020.04.28.066761. https://doi.org/10.1101/2020.04.28.066761.

(17) Cagno, V.; Tseligka, E. D.; Jones, S. T.; Tapparel, C. Heparan Sulfate Proteoglycans and Viral Attachment: True Receptors or Adaptation Bias? Viruses 2019, 11 (7). https://doi.org/10.3390/v11070596.

(18) Park, S.; Barnes, R.; Lin, Y.; Jeon, B.; Najafi, S.; Delaney, K. T.; Fredrickson, G. H.; Shea, J.-E.; Hwang, D. S.; Han, S. Dehydration Entropy Drives Liquid-Liquid Phase Separation by Molecular Crowding. Communications Chemistry 2020, 3 (1), 1-12. https://doi.org/10.1038/s42004-020-0328-8.

(19) Sterling, J. D.; Baker, S. M. A Continuum Model of Mucosa with Glycan-Ion Pairing. Macromolecular Theory and Simulations 2018, 27 (2), 1700079. https://doi.org/10.1002/mats.201700079.

(20) Dukhin, S. S.; Zimmermann, R.; Werner, C. Intrinsic Charge and Donnan Potentials of Grafted Polyelectrolyte Layers Determined by Surface Conductivity Data. J Colloid Interface Sci 2004, 274 (1), 309-318. https://doi.org/10.1016/j.jcis.2003.11.016.

(21) Barbati, A. C.; Kirby, B. J. Soft Diffuse Interfaces in Electrokinetics - Theory and Experiment for Transport in Charged Diffuse Layers. Soft Matter 2012, 8 (41), 1059810613. https://doi.org/10.1039/C2SM26121A.

(22) Schnitzer, J. E. Glycocalyx Electrostatic Potential Profile Analysis: Ion, PH, Steric, and Charge Effects. Yale J Biol Med 1988, 61 (5), 427-446.

(23) Stace, T. M.; Damiano, E. R. An Electrochemical Model of the Transport of Charged Molecules through the Capillary Glycocalyx. Biophys J 2001, 80 (4), 1670-1690.

(24) Zimmermann, R.; Kuckling, D.; Kaufmann, M.; Werner, C.; Duval, J. F. L. Electrokinetics of a Poly(N-Isopropylacrylamid-Co-Carboxyacrylamid) Soft Thin Film: Evidence of 
Diffuse Segment Distribution in the Swollen State. Langmuir 2010, 26 (23), 18169-18181. https://doi.org/10.1021/la103526b.

(25) Zimmermann, R.; Gunkel-Grabole, G.; Bünsow, J.; Werner, C.; Huck, W. T. S.; Duval, J. F. L. Evidence of Ion-Pairing in Cationic Brushes from Evaluation of Brush Charging and Structure by Electrokinetic and Surface Conductivity Analysis. J. Phys. Chem. C 2017, 121 (5), 2915-2922. https://doi.org/10.1021/acs.jpcc.6b12531.

(26) Sterling, J. D.; Baker, S. M. Electro-Lyotropic Equilibrium and the Utility of Ion-Pair Dissociation Constants. Colloid and Interface Science Communications 2017, 20, 9-11. https://doi.org/10.1016/j.colcom.2017.08.002.

(27) Xu, X.; Mastropietro, D.; Ruths, M.; Tirrell, M.; Yu, J. Ion-Specific Effects of Divalent Ions on the Structure of Polyelectrolyte Brushes. Langmuir 2019, 35 (48), 15564-15572. https://doi.org/10.1021/acs.langmuir.9b01984.

(28) Pincus, P. Colloid Stabilization with Grafted Polyelectrolytes. Macromolecules 1991, 24 (10), 2912-2919. https://doi.org/10.1021/ma00010a043.

(29) Farina, R.; Laugel, N.; Pincus, P.; Tirrell, M. Brushes of Strong Polyelectrolytes in Mixed Mono- and Tri-Valent Ionic Media at Fixed Total Ionic Strengths. Soft Matter 2013, 9 (44), 10458. https://doi.org/10.1039/c3sm51450a.

(30) Mallajosyula, S. S.; Guvench, O.; Hatcher, E.; MacKerell, A. D. CHARMM Additive AllAtom Force Field for Phosphate and Sulfate Linked to Carbohydrates. J Chem Theory Comput 2012, 8 (2), 759-776. https://doi.org/10.1021/ct200792v.

(31) Guvench, O.; Hatcher, E.; Venable, R. M.; Pastor, R. W.; MacKerell, A. D. CHARMM Additive All-Atom Force Field for Glycosidic Linkages between Hexopyranoses. J. Chem. Theory Comput. 2009, 5 (9), 2353-2370. https://doi.org/10.1021/ct900242e.

(32) Raman, E. P.; Guvench, O.; MacKerell, A. D. CHARMM Additive All-Atom Force Field for Glycosidic Linkages in Carbohydrates Involving Furanoses. J Phys Chem B 2010, 114 (40), 12981-12994. https://doi.org/10.1021/jp105758h.

(33) Guvench, O.; Mallajosyula, S. S.; Raman, E. P.; Hatcher, E.; Vanommeslaeghe, K.; Foster, T. J.; Jamison, F. W.; Mackerell, A. D. CHARMM Additive All-Atom Force Field for Carbohydrate Derivatives and Its Utility in Polysaccharide and Carbohydrate-Protein Modeling. J Chem Theory Comput 2011, 7 (10), 3162-3180. https://doi.org/10.1021/ct200328p.

(34) Aytenfisu, A. H.; Yang, M.; MacKerell, A. D. CHARMM Drude Polarizable Force Field for Glycosidic Linkages Involving Pyranoses and Furanoses. J. Chem. Theory Comput. 2018, 14 (6), 3132-3143. https://doi.org/10.1021/acs.jctc.8b00175.

(35) Yoo, J.; Aksimentiev, A. Improved Parametrization of $\mathrm{Li}+, \mathrm{Na}+, \mathrm{K}+$, and $\mathrm{Mg} 2+$ Ions for All-Atom Molecular Dynamics Simulations of Nucleic Acid Systems. J. Phys. Chem. Lett. 2012, 3 (1), 45-50. https://doi.org/10.1021/jz201501a.

(36) Jo, S.; Kim, T.; Iyer, V. G.; Im, W. CHARMM-GUI: A Web-Based Graphical User Interface for CHARMM. Journal of Computational Chemistry 2008, 29 (11), 1859-1865. https://doi.org/10.1002/jcc.20945. 
(37) Jo, S.; Song, K. C.; Desaire, H.; MacKerell, A. D.; Im, W. Glycan Reader: Automated Sugar Identification and Simulation Preparation for Carbohydrates and Glycoproteins. J Comput Chem 2011, 32 (14), 3135-3141. https://doi.org/10.1002/jcc.21886.

(38) Park, S.-J.; Lee, J.; Patel, D. S.; Ma, H.; Lee, H. S.; Jo, S.; Im, W. Glycan Reader Is Improved to Recognize Most Sugar Types and Chemical Modifications in the Protein Data Bank. Bioinformatics 2017, 33 (19), 3051-3057. https://doi.org/10.1093/bioinformatics/btx358.

(39) Park, S.-J.; Lee, J.; Qi, Y.; Kern, N. R.; Lee, H. S.; Jo, S.; Joung, I.; Joo, K.; Lee, J.; Im, W. CHARMM-GUI Glycan Modeler for Modeling and Simulation of Carbohydrates and Glycoconjugates. Glycobiology 2019, 29 (4), 320-331.

https://doi.org/10.1093/glycob/cwz003.

(40) Pronk, S.; Páll, S.; Schulz, R.; Larsson, P.; Bjelkmar, P.; Apostolov, R.; Shirts, M. R.; Smith, J. C.; Kasson, P. M.; van der Spoel, D.; Hess, B.; Lindahl, E. GROMACS 4.5: A HighThroughput and Highly Parallel Open Source Molecular Simulation Toolkit. Bioinformatics 2013, 29 (7), 845-854. https://doi.org/10.1093/bioinformatics/btt055.

(41) Jorgensen, W. L.; Chandrasekhar, J.; Madura, J. D.; Impey, R. W.; Klein, M. L. Comparison of Simple Potential Functions for Simulating Liquid Water. J. Chem. Phys. 1983, 79 (2), 926-935. https://doi.org/10.1063/1.445869.

(42) Essmann, U.; Perera, L.; Berkowitz, M. L.; Darden, T.; Lee, H.; Pedersen, L. G. A Smooth Particle Mesh Ewald Method. J. Chem. Phys. 1995, 103 (19), 8577-8593. https://doi.org/10.1063/1.470117.

(43) Aksimentiev, A.; Schulten, K. Imaging $\alpha$-Hemolysin with Molecular Dynamics: Ionic Conductance, Osmotic Permeability, and the Electrostatic Potential Map. Biophys J 2005, 88 (6), 3745-3761. https://doi.org/10.1529/biophysj.104.058727.

(44) Venable, R. M.; Luo, Y.; Gawrisch, K.; Roux, B.; Pastor, R. W. Simulations of Anionic Lipid Membranes: Development of Interaction-Specific Ion Parameters and Validation Using NMR Data. J. Phys. Chem. B 2013, 117 (35), 10183-10192.

https://doi.org/10.1021/jp401512z.

(45) Bazant, M. Z.; Kilic, M. S.; Storey, B. D.; Ajdari, A. Towards an Understanding of InducedCharge Electrokinetics at Large Applied Voltages in Concentrated Solutions. Advances in Colloid and Interface Science 2009, 152 (1), 48-88.

https://doi.org/10.1016/j.cis.2009.10.001.

(46) Grahame, D. C. Effects of Dielectric Saturation upon the Diffuse Double Layer and the Free Energy of Hydration of Ions. J. Chem. Phys. 1950, 18 (7), 903-909. https://doi.org/10.1063/1.1747807.

(47) Gupta, A.; Stone, H. A. Electrical Double Layers: Effects of Asymmetry in Electrolyte Valence on Steric Effects, Dielectric Decrement, and Ion-Ion Correlations. Langmuir 2018, 34 (40), 11971-11985. https://doi.org/10.1021/acs.langmuir.8b02064. 
(48) López-García, J. J.; Horno, J.; Grosse, C. Multiionic and Permittivity-Related Effects on the Diffuse Electric Double Layer Structure at Solid-Electrolyte Solution Interfaces https://www.hindawi.com/journals/amse/2018/4316894/ (accessed Mar 1, 2020). https://doi.org/10.1155/2018/4316894.

(49) Vezzani, D.; Bandini, S. Donnan Equilibrium and Dielectric Exclusion for Characterization of Nanofiltration Membranes. Desalination 2002, 149 (1), 477-483. https://doi.org/10.1016/S0011-9164(02)00784-1.

(50) Stirnemann, G.; Wernersson, E.; Jungwirth, P.; Laage, D. Mechanisms of Acceleration and Retardation of Water Dynamics by Ions. J. Am. Chem. Soc. 2013, 135 (32), 11824-11831. https://doi.org/10.1021/ja405201s.

(51) Ben-Yaakov, D.; Andelman, D.; Podgornik, R. Dielectric Decrement as a Source of IonSpecific Effects. J. Chem. Phys. 2011, 134 (7), 074705. https://doi.org/10.1063/1.3549915.

(52) Hribar, B.; Southall, N. T.; Vlachy, V.; Dill, K. A. How Ions Affect the Structure of Water. J. Am. Chem. Soc. 2002, 124 (41), 12302-12311. https://doi.org/10.1021/ja026014h.

(53) Andreev, M.; de Pablo, J. J.; Chremos, A.; Douglas, J. F. Influence of Ion Solvation on the Properties of Electrolyte Solutions. The Journal of Physical Chemistry B 2018, 122 (14), 4029-4034. https://doi.org/10.1021/acs.jpcb.8b00518.

(54) Gun'ko, V. M.; Savina, I. N.; Mikhalovsky, S. V. Properties of Water Bound in Hydrogels. Gels 2017, 3 (4), 37. https://doi.org/10.3390/gels3040037.

(55) van der Vegt, N. F. A.; Haldrup, K.; Roke, S.; Zheng, J.; Lund, M.; Bakker, H. J. WaterMediated Ion Pairing: Occurrence and Relevance. Chem. Rev. 2016, 116 (13), 7626-7641. https://doi.org/10.1021/acs.chemrev.5b00742.

(56) Boström, M.; Williams, D. R. M.; Ninham, B. Specific Ion Effects: Why DLVO Theory Fails for Biology and Colloid Systems. Physical review letters 2001, 87, 168103. https://doi.org/10.1103/PhysRevLett.87.168103.

(57) Lo Nostro, P.; Ninham, B. W. Hofmeister Phenomena: An Update on Ion Specificity in Biology. Chem Rev 2012, 112 (4), 2286-2322. https://doi.org/10.1021/cr200271j.

(58) Seal, S.; Doblhoff-Dier, K.; Meyer, J. Dielectric Decrement for Aqueous NaCl Solutions: Effect of Ionic Charge Scaling in Nonpolarizable Water Force Fields. J Phys Chem B 2019 , 123 (46), 9912-9921. https://doi.org/10.1021/acs.jpcb.9b07916.

(59) Kirby, B. J.; Jungwirth, P. Charge Scaling Manifesto: A Way of Reconciling the Inherently Macroscopic and Microscopic Natures of Molecular Simulations. J. Phys. Chem. Lett. 2019, 10 (23), 7531-7536. https://doi.org/10.1021/acs.jpclett.9b02652.

(60) Tolmachev, D. A.; Boyko, O. S.; Lukasheva, N. V.; Martinez-Seara, H.; Karttunen, M. Overbinding and Qualitative and Quantitative Changes Caused by Simple $\mathrm{Na}+$ and $\mathrm{K}+$ Ions in Polyelectrolyte Simulations: Comparison of Force Fields with and without NBFIX and ECC Corrections. J. Chem. Theory Comput. 2020, 16 (1), 677-687. https://doi.org/10.1021/acs.jctc.9b00813.

(61) Marcus, Y.; Hefter, G. Ion Pairing. Chem. Rev. 2006, 106 (11), 4585-4621. https://doi.org/10.1021/cr040087x. 
(62) Roy, S.; Baer, M. D.; Mundy, C. J.; Schenter, G. K. Marcus Theory of Ion-Pairing. J. Chem. Theory Comput. 2017, 13 (8), 3470-3477. https://doi.org/10.1021/acs.jctc.7b00332.

(63) Zhulina, E. B.; Birshtein, T. M.; Borisov, O. V. Theory of Ionizable Polymer Brushes. Macromolecules 1995, 28 (5), 1491-1499. https://doi.org/10.1021/ma00109a021.

(64) Dzubiella, J.; Fyta, M.; Horinek, D.; Kalcher, I.; Netz, R. R.; Schwierz, N. Ion-Specificity: From Solvation Thermodynamics to Molecular Simulations and Back. In Specific Ion Effects; WORLD SCIENTIFIC, 2009; pp 231-265. https://doi.org/10.1142/9789814271585_0009.

(65) Collins, K. D. The Behavior of Ions in Water Is Controlled by Their Water Affinity. Quarterly Reviews of Biophysics 2019, 52. https://doi.org/10.1017/S0033583519000106.

(66) Nagarajan, A.; Malvi, P.; Wajapeyee, N. Heparan Sulfate and Heparan Sulfate Proteoglycans in Cancer Initiation and Progression. Front. Endocrinol. 2018, 9. https://doi.org/10.3389/fendo.2018.00483.

(67) Lawrence, R.; Yabe, T.; HajMohammadi, S.; Rhodes, J.; McNeely, M.; Liu, J.; Lamperti, E. D.; Toselli, P. A.; Lech, M.; Spear, P. G.; Rosenberg, R. D.; Shworak, N. W. The Principal Neuronal GD-Type 3-O-Sulfotransferases and Their Products in Central and Peripheral Nervous System Tissues. Matrix Biol 2007, 26 (6), 442-455. https://doi.org/10.1016/j.matbio.2007.03.002.

(68) Eigen, M.; Tamm, K. Schallabsorption in Elektrolytlösungen als Folge chemischer Relaxation I. Relaxationstheorie der mehrstufigen Dissoziation. Zeitschrift für Elektrochemie, Berichte der Bunsengesellschaft für physikalische Chemie 1962, 66 (2), 93107. https://doi.org/10.1002/bbpc.19620660205.

(69) Boda, D.; Henderson, D.; Gillespie, D. The Role of Solvation in the Binding Selectivity of the L-Type Calcium Channel. J Chem Phys 2013, 139 (5), 055103. https://doi.org/10.1063/1.4817205.

(70) Liu, X.; Lu, B. Incorporating Born Solvation Energy into the Three-Dimensional PoissonNernst-Planck Model to Study Ion Selectivity in KcsA K ${ }^{+}$Channels. Phys. Rev. E 2017, 96 (6), 062416. https://doi.org/10.1103/PhysRevE.96.062416.

(71) Fennell, C. J.; Bizjak, A.; Vlachy, V.; Dill, K. A. Ion Pairing in Molecular Simulations of Aqueous Alkali Halide Solutions. J. Phys. Chem. B 2009, 113 (19), 6782-6791. https://doi.org/10.1021/jp809782z.

(72) Chen, A. A.; Pappu, R. V. Quantitative Characterization of Ion Pairing and Cluster Formation in Strong 1:1 Electrolytes. J. Phys. Chem. B 2007, 111 (23), 6469-6478. https://doi.org/10.1021/jp0708547. 
TABLE OF CONTENTS IMAGE

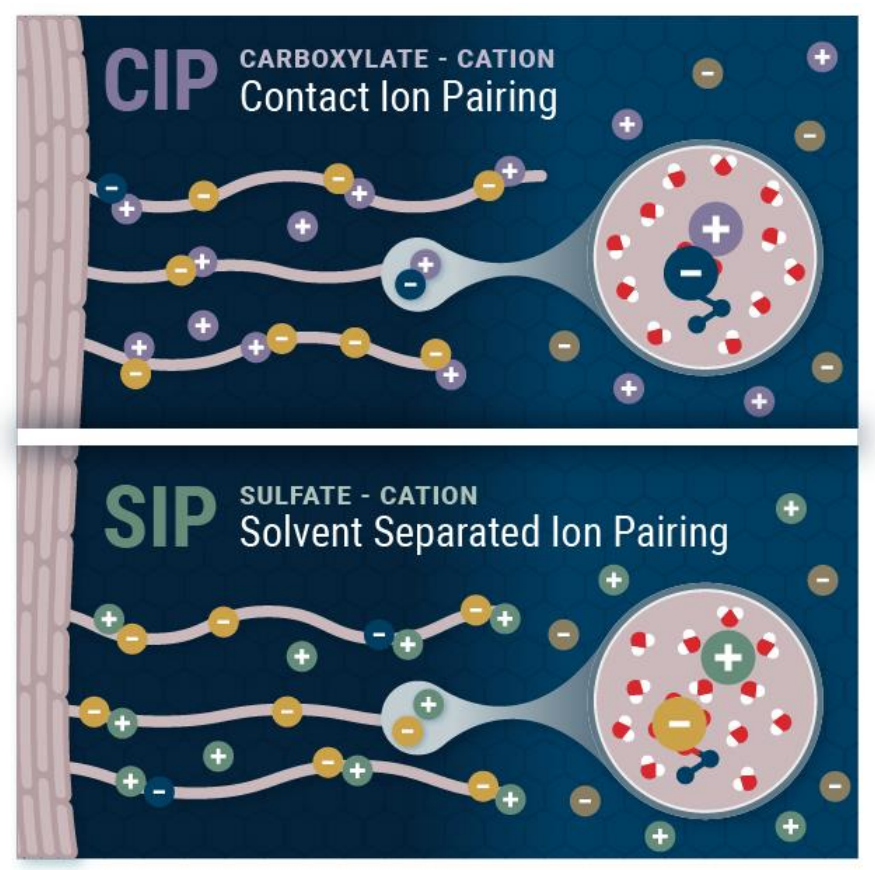

KEYWORDS glycosaminoglycan, Donnan potential, Born solvation, dielectric decrement, polyelectrolyte brush 